\title{
MINERALOGICAL CHARACTERIZATION OF JUVENTAE CHASMA, MARS: EVIDENCES FROM MRO-CRISM
}

\author{
Mahima Singh", V.J. Rajesh \\ Indian Institute of Space Science and Technology, Department of Earth and Space Science, Trivandrum, India- \\ mahimasingh.12@iist.ac.in
}

KEY WORDS: Juventae Chasma, Hydrous Sulphates, Mafic minerals, Carbonates, Light Toned Layered Deposits, CRISM

\begin{abstract}
:
Juventae Chasma is a long depression associated with Valles Marineris and this study discusses the spectral observation made after analysing the Mars Reconnaissance Orbiter (MRO) Compact Reconnaissance Imaging Spectrometer for Mars (CRISM) Full Resolution targeted (FRT) Images in the wavelength region of 1000-2600 nm. Observations reveal the presence of hydrous sulphates, pyroxenes (mafic minerals) and silica rich minerals, more likely opaline silica or glass. Hydrous mineral identified shows the absorption bands, which are more consistent with gypsum. Absorption bands at 2300-2350 nm, and 2500-2550 nm, which are characteristics of carbonates, have been also identified in the region. Presence of this mineral assemblage, confirmed by the observed spectral signatures ranging from volcanic to sedimentary origin, implies a relatively geologically active area, and a significant region in terms of aqueous activity.
\end{abstract}

\section{INTRODUCTION}

Juventae Chasma is a box canyon and located north of Valles Marineris. Generally, it is considered as a part of Valles Marineris system, but is separated from the main channel by $500 \mathrm{~km}$. Deposits of Juventae Chasma has been studied by using Mars Global Surveyor (MGS), Mars Orbiter Camera (MOC) and Mars Odyssey Thermal Emission Imaging System (THEMIS) data, Mars Reconnaissance Orbiter (MRO) Compact Reconnaissance Imaging Spectrometer for Mars (CRISM) (Chapman et al., 2003; Catling et al., 2006; Bishop et al., 2009). The surface of Juventae Chasma has been marked with the presence of mounds and plateau, towards the outflow of Maja Vallis (Chapman et al., 2003; Catling et al., 2006). Mineralogy of Juventae Chasma has been identified and marked with the presence of gypsum identified in horizontal layers nearly hundred meters in thickness each (Gendrin et al., 2005). Kieserite is found in the deposit, surrounding the gypsum deposits and is associated with other rough material at lower elevation (Gendrin et al., 2005). Later, the identified mineralogy shows the presence of sulphates on light toned layers, mafic minerals at bedrock and hydrated silica and ferric sulphate on plateau (Bishop et al., 2009, 2007a; Milliken et al., 2008). Juventae Chasma is $3 \mathrm{~km}$ long depression and likely to be formed due to stresses related to Tharsis rise during the late Noacian to early Hesperian period (Lucchitta et al., 1992; Chapman et al., 2003).

Various processes have been assigned to define the deposits in the region, which vary from volcanic (Chapman et al., 2003) to lacustrine or airfall deposits (Catling et al., 2006). Here we present CRISM data results from the mounds, basin floor and wall rock of Juventae Chasma, to get insights into the genesis of the minerals and inferences towards the palaeo-environmental conditions of the region, as it is always considered as one of the potential region to study the aqueous past of Mars. This study shows the identification of carbonates in the region, which will add and improve the model for the generation of the specific mineral assemblage.

\section{METHODOLOGY}

CRISM acquires images in high-resolution targeted mode using two detectors: a VNIR detector in the spectral range 360-1050 $\mathrm{nm}$ and an IR detector covering 1000-3900 nm (Murchie et al., 2007, 2009). Selected CRISM- Full Resolution Targeted (FRT) has been processed using the steps defined by the team over the first Mars year (Murchie et al., 2009). Firstly, the CRSIM data was converted to I/F by subtracting the instrument background, dividing by processed measurements of the internal calibration standard, and dividing by solar irradiance (Bishop et al., 2009). Then, images are processed using a cleaning algorithm to remove noise and large spikes within the data because of instrument effects [Parente, 2008]. Band math calculations have been performed to create a set of spectral parameters that distinguish specific features associated with mineral types [Pelkey et al., 2007]. Atmospheric correction was performed by a scaled atmospheric transmission spectrum derived from multiple observations over Olympus Mons. To avoid the irregularity in the spectrum profile, instead of pixel by pixel analysis, regions of interest were selected for better identification of spectral signatures. During the stage of processing of the data, the regions of interest with large noise and irregular spectra were avoided.

\section{RESULTS AND DISCUSSIONS}

CRISM images from Juventae Chasma (Fig.1) frt00017ae0 and frt00005814, used in this study have been taken from the mound and wall rock regions. Spectral signatures have been indicative of the presence of gypsum in the CRISM image frt00017ae0 (Fig 2a \& b). Main absorption bands identified are triplet absorption between $1440-1540 \mathrm{~nm}$, absorptions at 1900 $\mathrm{nm}$, and small absorption at $2250 \mathrm{~nm}$, all due to combinations and overtones of $\mathrm{H}_{2} \mathrm{O}$ vibrations and liberations (Hunt et al., 1971; Cloutis et al., 2006). One of the most prominent absorption bands is at $2400 \mathrm{~nm}$, which has been assigned to polyhydrated sulphates (Bishop et al., 2007).

\footnotetext{
* Corresponding Author
} 
The broad absorption band whose centre lie at around $2200 \mathrm{~nm}$ which correspond to the presence of pyroxenes in the region (Fig.3a \& b). Carbonates show diagnostic vibrational absorption-bands due to the $\mathrm{CO}_{3}{ }^{2-}$ ion at $2500-2550 \mathrm{~nm}$ and 2300-2350 nm (Van Der Meer, 2004). CRISM image frt00005814 also shows weak absorptions at 2300-2350 nm, and 2500-2550 $\mathrm{nm}$, which are diagnostic feature of carbonates. Therefore, the images adjacent to the image frt00005814 could be also processed in further studies for better identification of carbonates, because till now only mono to poly hydrous sulphates, opaline silica and mafic minerals has been reported (Bishop et al., 2009).

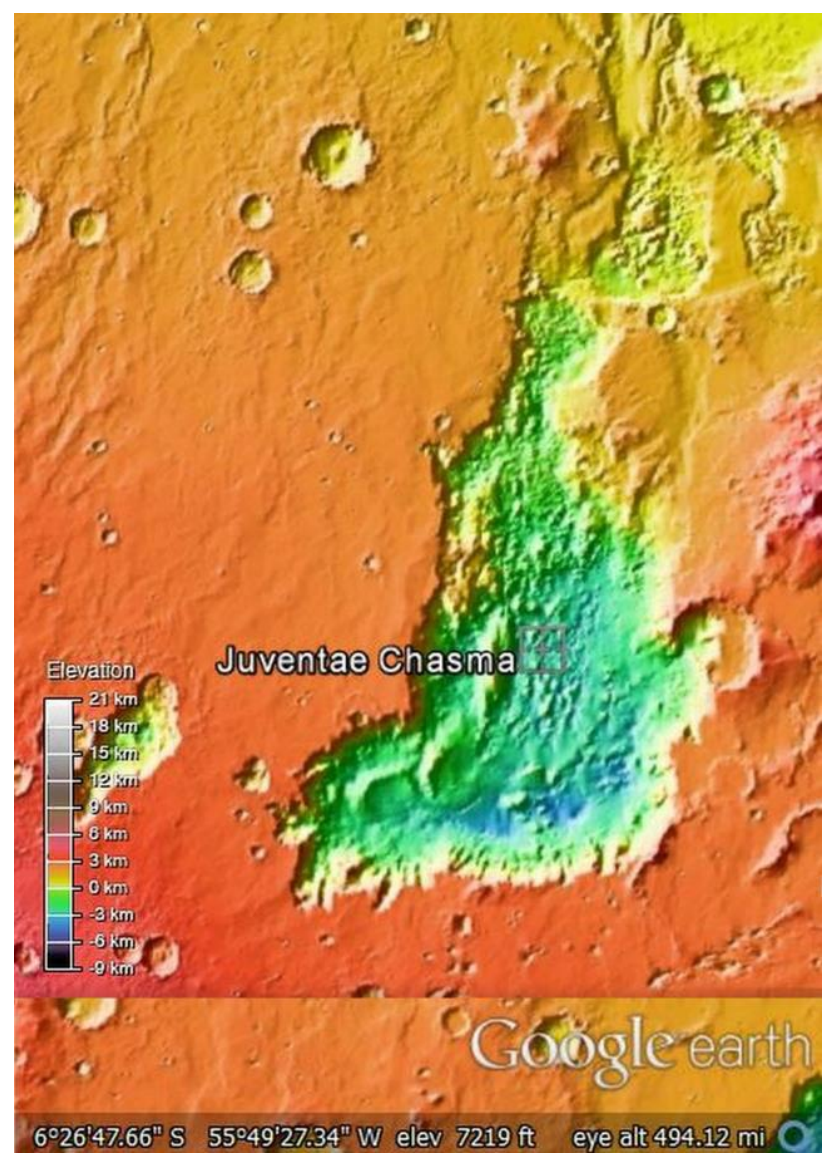

Figure 1. Location and morphological features of Juventae Chasma, Mars; extracted from Google Earth.

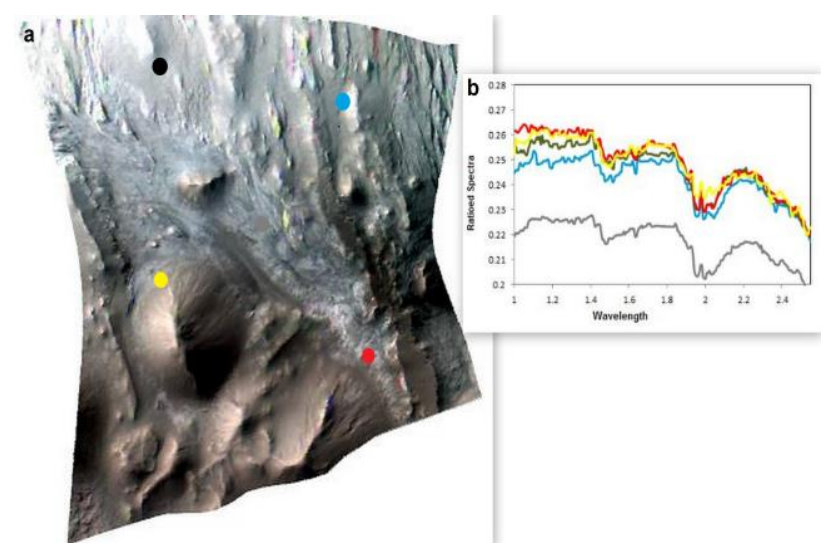

Figure 2. (a) CRISM image frt00017ae0 showing locations of extracted spectra. (b) Spectral signatures derived from the

CRISM Image frt00017ae0.

The palaeo-environmental conditions of the region have been developed by many scientists. On the basis of the mineral chemistry and morphological characteristics; Bishop et al., (2009) have suggested acidic aqueous environment in Hesperian time (Bishop et al., 2009). Therefore, identification of other aqueous minerals could add the information to interpret the palaeo-environment of whole sequence of deposit and better model for the formation of identified minerals.

These spectra can work for the spectral library of CRISM data. Earth is also marked with similar canyon features, therefore to better interpret the deposits of Juventae Chasma, one selected site could also be studied in detail to explain the palaeoenvironmental conditions of the region.

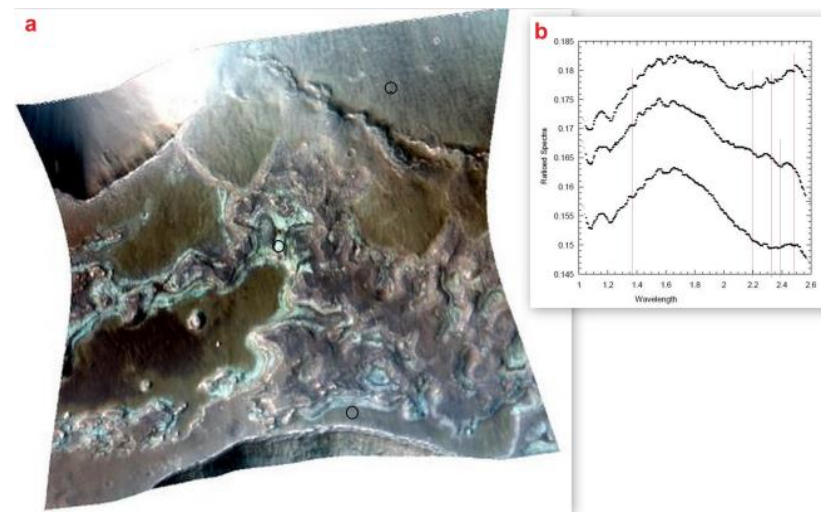

Figure 3. CRISM image frt00005814 showing locations of extracted spectra. (b) Spectral signatures derived from the CRISM Image frt00005814.

\section{SUMMARY}

The conclusions drawn out of the study are:

1) Juventae Chasma is mainly composed of hydrous sulphates and marked by the presence of mafic minerals of pyroxene family,

2) Spectral signatures of the region shows the absorptions at $2300-2350 \mathrm{~nm}$, and $2500-2550 \mathrm{~nm}$, which could be linked to the presence of carbonates, and

3) Deposits of the region could be studied further to get the actual measures regarding the palaeo-hydration activity in the region and water chemistry in which the deposits have been formed.

\section{ACKNOWLEDGEMENTS}

We gratefully acknowledge Dr. Prakash Chauhan and Nirmala Jain, Space Application Centre, Ahmedabad, Gujarat for their invaluable assistance during the learning phase of CRISM data analysis and discussions which have contributed to make the study happened. Additionally, I would also like to thank head of the Earth and Space Science Department, Prof. A. Chandrasekar and Director, Dr. KS Dasgupta, Indian Institute of Space Science and Technology, Trivandrum for their continuous support and encouragement. We extend our heartiest gratitude 
to the CRISM and MRO operation team for collecting the data that made the results in this paper possible.

\section{REFERENCES}

Bishop, J. L., et al. (2007a). Sulfates and mafic minerals in Juventae Chasma as seen by CRISM in coordination with OMEGA, HiRISE and Context images, in Seventh International Conference on Mars, July 9- 13, 2007, Pasadena CA [CDROM], LPI Contrib., 1353, Abstract 3350.

Bishop, J. L., Parente, M., Weitz, C. M., Noe Dobrea, E. Z., Roach, L. H., Murchie, S. L., ... \& Mustard, J. F. (2009). Mineralogy of Juventae Chasma: Sulfates in the light-toned mounds, mafic minerals in the bedrock, and hydrated silica and hydroxylated ferric sulfate on the plateau. Journal of Geophysical Research: Planets (1991-2012), 114(E2).

Catling, D. C., S. E. Wood, C. B. Leovy, D. R. Montgomery, H. M. Greenberg, C. R. Glein, and J. M. Moore (2006). Lighttoned layered deposits in Juventae Chasma, Mars, Icarus, 181, 26-51, doi:10.1016/j.icarus.2005.10.020.

Chapman, M. G., M. T. Gudmundsson, A. J. Russell, and T. M. Hare, 2003. Possible Juventae Chasma subice volcanic eruptions and Maja Valles ice outburst floods on Mars: Implications of Mars Global Surveyor crater densities, geomorpholoy, and topography, J. Geophys. Res., 108(E10), 5113, doi:10.1029/2002JE002009.

Cloutis, E. A., et al. (2006). Detection and discrimination of sulfate minerals using reflectance spectroscopy, Icarus, 184, $121-157$.

Gendrin, A., et al., 2005, Sulfates in Martian layered terrains: The OMEGA/Mars Express view, Science, 307, 1587 - 1591, doi:10.1126/science. 1109087 .

Lucchitta, B. K., A. S. McEwen, G. D. Clow, P. E. Geissler, R. B. Singer, R. A. Schultz, and S. W. Squyres (1992). The canyon system on Mars, in Mars, edited by H. H. Kieffer et al., pp. 453- 492, Univ. of Ariz. Press, Tucson.

Milliken, R. E., et al. (2008). Opaline silica in young deposits on Mars, Geology, 36(11), 847-850, doi:10.1130/G24967A.24961.

Murchie, S. L., et al. (2009a). Evidence for the origin of layered deposits in Candor Chasma, Mars, from mineral composition and hydrologic modeling, J. Geophys. Res., 114, E00D05, doi:10.1029/2009JE003343.

Murchie, S., et al. (2007). Compact Reconnaissance Imaging Spectrometer for Mars (CRISM) on Mars Reconnaissance Orbiter (MRO), J. Geophys. Res., 112, E05S03, doi: 10.1029/2006JE002682.

Hunt, G.R., Salisbury, J.W., Lenhoff, C.J., (1971).Visible and near-infrared spec- tra of minerals and rocks. VI. Sulfides and sulfates. Mod. Geol. 3, 1-14.

Parente, M., (2008), A new approach to denoising CRISM images, Lunar Planet. Sci., XXXIX, Abstract 2528.

Pelkey, S. M., et al. (2007), Parameterizing mineral diversity on mars from reflectance, J. Geophys. Res., 112, E08S14, doi:10.1029/2006JE002831.
Van Der Meer, F. (2004). Analysis of spectral absorption features in hyperspectral imagery. International Journal of Applied Earth Observation and Geoinformation, 5(1), 55-68.

Revised November 2014 